\title{
Towards understanding the Effect of Oil on Phytoremediation of PCB Co- Contamination in Transformer Oil Using Chromolaena Odorata
}

\author{
R. O. Anyasi' ${ }^{1}$, H. I. Atagana ${ }^{2}$ \\ ${ }^{1}$ Department of Environmental Sciences, University of South Africa, \\ Pretoria, South Africa \\ ${ }^{2}$ Institute for Science and Technology Education, University of South Africa \\ Pretoria, South Africa \\ eanyasro@unisa.ac.za; atagahi@unisa.ac.za
}

\begin{abstract}
This study involves the greenhouse assessment of the effect of oil on Chromolaena odorata ability to remove PCB from soil treated with transformer oil co-contaminated with Aroclor 1260. Plants were transplanted into one kilogram of soil contained in $1 \mathrm{~L}$ pots differently containing 100, 200, and $500 \mathrm{ml}$ of transformer oil (T/O), co-contaminated with $100 \mathrm{ppm}$ of Aroclor. Treatment was done in two microcosm; direct contamination and soil culture method. Measured plant growth parameters showed that $C$. odorata growth was differently affected by the different concentrations of transformer oil. Inhibition of the oil to plant growth increased with concentration. At the end of six weeks of growth, plants showed a diminished effect in T/O amended soil to the parameters tested. Plants size was increased by 1.4, 0.46 and $-1.0 \%$ in direct treatment and 17.01, 6.09 and $1.08 \%$ in soil culture at the 100, 200 and 500 ppm respectively. Untreated control showed $43.07 \%$ increase. Slight PCB recovery was observed in the root tissues of C. odorata but the plant caused a high reduction of $66.6,53.2,41.5 \%$ and $77.3,74.7,58.8 \%$ of soil PCB at both treatments with their respective concentration of oil. However, unplanted control was reduced by 21.4 and $16.7 \%$ in the two treatments at 100 ppm of oil. This study has shown that with improved agronomic practices, there is possibility of phytoremediation of soil PCB from PCB contained transformer oil contaminated soil using Chromolaena odorata, hence should be optimized in the field.
\end{abstract}

Keywords: Phytoremediation, Transformer oil contamination, Chromolaena odorata, PCB, Soil remediation, South Africa.

\section{Introduction}

Advances in science and technology have enabled man to exploit natural resources largely, generating unprecedented disturbances in global elemental cycles [1]. The relatively recent introduction of man-made toxic chemicals, and the massive relocation of natural materials to different environmental compartments; soil, ground water, and atmosphere, has resulted in severe pressure on the self-cleansing capacity of recipient ecosystems. Various accumulated pollutants are of concern relative to both human and ecosystem exposure and potential impact [2]. There have been efforts by many authorities in different countries to control the release of contaminants, and to accelerate the breakdown of existing contaminants by appropriate remediation techniques. Such techniques and technologies are marred by various disadvantages and usually require relatively high capital expenditure and man power as well as long term operating cost. Hence, recent interests are geared towards developing more cost effective approach to treat large volumes of contaminated natural resources such as soil, ground water and wetlands [3].

Bioremediation is the use of plants and the associated rhizospheric microorganisms to remove, transform, or contain toxic chemicals located in soils, sediments, ground water, surface water, and even the atmosphere [4]. This technique is currently used to treat many classes of contaminants including petroleum hydrocarbons, chlorinated solvents, pesticides, explosives, heavy metals and radionuclides, and landfill leachates [5-6]. In the present study, C. odorata_(Siam weed), was grown in Aroclor 1260 amended transformer oil-contaminated soil in order to study the effect of oil on the ability of plants in the remediation of soil-PCB from a transformer oil impacted soil. This is of importance as literatures have only reported on plants remediation of $\mathrm{PCB}$ without considering the impact of co-contamination of the oil, considering the fact that PCB has not been used in isolation [8] 
Polychlorinated biphenyls (PCBs) are a family of anthropogenic organic compounds that is persistent in the environment causing its bioaccumulative phenomenon that enables the contaminant to be found in every part of the environment. PCB is commercially produced by direct chlorination of biphenyls [2]. A good commercial form of PCB is Aroclor 1254 and 1260, although other brand names exist [7-9].

Transformer oil also known as insulating oil is a highly refined mineral oil that is stable at high temperatures and usually possesses excellent electrical insulating properties. Properties of transformer oil in transformers require periodic testing to make sure that the basic electrical properties of the oil are intact as it is in operation. This informs the filtration and regeneration activities on transformers [5].

Various traditional remediation measures for example chemical (treatment with solvents); mechanical (soil excavation), thermal (incineration), and biological (use of microorganisms), have been used for the elimination of PCBs and other organics from the environment [11]. These remediation techniques have been successful in the remediation of organic contaminants, but are marred by various disadvantages. These include the fact that the processes are expensive, some of the processes are slow hence targets only the low chlorinated biphenyls, others live the finger print of other more toxic compounds at the end as a result are not environmentally friendly and lacks general public acceptability [12]. It is therefore imperative to develop a more cost effective technique for the treatment of complex PCB as contained in transformer oil.

Plants are known to take up large amount of water with nutrient from soil in soluble form in order to increase in biomass. This phenomenon has been investigated to be of benefits in the removal of pollutants from the environment and is referred to as phytoremediation [12-16]. Phytoremediation is the use of vegetation for in situ treatment of contaminants from soil and water body. It is a promising technique that can be used to manage pollution [9]. Phytoremediation is cost effective and eco-friendly strategy that can complement or replace conventional approaches especially in the remediation of soil contaminated by PCBs. The principle mechanism of phytoremediation is either by stimulation of soil microbial activity and degradation of contaminants or through plant uptake of contaminants or by even their degradation products [11-12, 18-19]

Chlomolaena odorata (L) R.M. King \& H. Robinson (Siam weed) is an invasive bushy shrub of South American origin. The plant is a member of the tribe Eupatoreae in the sunflower family Asteraceae and is been regarded as one of the most notorious invasive alien plant in the plant community [8]. C. odorata have been found to possess amongst its strong morphological status, to possess most qualities of a phytoremediation plant. These features are responsible for the plant's success as invasive specie in its new environments. These factors therefore present $C$. odorata as a potential plant for phytoremediation of a complex organic system as seen in the co-contamination of oil with Aroclor [2].

The interest in transformer oil arose as a result of the fact that $\mathrm{T} / \mathrm{O}$ is one of the most widely used organic chemicals and the unscrupulous discharge of the oil calls for concern. However, T/O is linked with PCB contamination and has contributed in the continued proliferation of PCB in the environment. At present, little information is known regarding the treatment of transformer oil contaminated soil using phytoremediation processes [1]. Thus this study aimed to investigate the effect of oil on the ability of Chromolaena odorata to phytoremediate soil-PCB from transformer oil co-contaminated Aroclor 1260 treated soil under greenhouse conditions.

\section{Material and methods.}

\subsection{Soil}

Soil samples were collected from a depth of up to $30 \mathrm{~cm}$, from the main campus of University of South Africa, Pretoria. The soil samples were homogenized with hand to remove pebbles, stones and gravels and, air dried, before it was put in cellophane bags and stored at $4^{\circ} \mathrm{C}$ before use.

\subsection{Plants}

Chromolaena odorata plants were collected from the Department of Botany University of KwaZulu-Natal Pietermaritzburg and propagated by stem cuttings in the greenhouse at the University of South Africa. Soil samples were mixed with animal manure that was obtained from the Department of Veterinary Science, University of Pretoria, 
Onderstepoort, at the ratio of 9:1. The bed was watered manually using watering can to maintain $70 \%$ moisture at field capacity.

\subsection{PCB and transformer oil}

Commercial PCB in form of Aroclor 1260 in surrogate standard concentration of $1000 \mathrm{ppm}$ in hexane was supplied by Sigma Aldreich-Germany, and used Transformer oil (T/O) was provided by City power Johannesburg-South Africa and new oil (Nynas-LYRA X) supplied by Nynas oil- Sweden.

\subsection{Treatments}

1. Transformer oil direct treatment samples $\left(\mathrm{T} / \mathrm{O}_{\mathrm{D}}\right)$ and

2. Transformer oil culture Suzuki samples $\left(\mathrm{T} / \mathrm{O}_{\mathrm{S}}\right)$.

\subsection{Control samples}

1. Soil samples planted without contamination to test the toxicity of the contaminants on plants (C1);

2. Soil samples contaminated without plants to test for other possible measures of dissipation of the contaminants $(\mathrm{C} 2)$;

\subsection{Experimental design}

42 set of PVC pot were used for the experiment each filled with $1 \mathrm{~kg}$ of soil. The pots were divided into two (21 each for the two transformer oil treatments), each section were further divided into six (3) replicates each for the treatments and controls). Thus, three (3) $C$. odorata plants were tested in two (2) pollutants among six (6) treatments replicated into three (3). A total of one hundred and twenty six plants were used in the study.

\subsection{Experimental procedures}

Five weeks old $C$. odorata plants were used in this study; the plants were transplanted into contaminated soil according to the treatment and were allowed for six weeks. In T/O direct treatments, plants were directly transplanted into the $\mathrm{T} / \mathrm{O}_{\mathrm{D}}$ treated soil samples. In Suzuki (sprout culture adopted from Suzuki et al, [35] method however, plants were transplanted in a cultured soil which is contained in cellophane bags with holes at the bottom for protrusion of the roots. The bags containing the cultured soil and plants with protruded roots were placed on T/O treated soil contained in the PVC cups. This adopted and amended Suzuki method was designed to avoid the toxic effects of T/O on plants which posed a problem during the preliminary stage of the study. The initial length and number of mature leaves per plants (MLPP) was noted. The experiment was allowed for six weeks at prevailing environmental conditions, watered to maintain moisture at $75 \%$ field capacity with manual watering can. Effort was made at ensuring that watering was done in such a way as to only wet the soil at any point in time avoiding much run off, weeds were removed manually at intervals. Measurements were also made at weekly intervals for the plant length, MLPP, leaf colour at different treatments and the root length which was only measured on the day of harvest. There was no application of inorganic manures to the soil mixes, but organic animal compost was used during the preparation of the soil at the ratio 1:9 manure to soil.

\subsection{Sampling}

After six weeks of growth of the plant in the contaminated and control set up, the soil and plants were sampled. The plants were removed carefully from the pots after loosening the soil around the pot using a kitchen knife; the roots were separated from the soil by shaking off the soil leaving the only adhering particles of the soil regarded as the rhizosphere soil. During this process, the entire plants were washed using running tape water, rinsed with distilled water and allowed to air dry, it was weighed afterwards to get the wet biomass and root lengths were measured. The plants were then separated into leaf, stem and roots, and the entire samples weighed using Mettler Toledo balance model PB1502 with maximum capacity of $1510 \mathrm{~g}$. The soil samples were carefully collected also, homogenized and divided into sets together with the plants samples in preparation for subsequent extraction and analysis. All cuttings of the plants were done with a kitchen knife rinsed with acetone between uses to minimize cross contamination. Harvested and prepared plant samples were kept in Whirlpak ${ }^{\mathrm{TM}}$ bags; Nasco-South Africa, in the refrigerator until time for analysis. Before the analysis, composite samples of the plant tissues were oven dried for the determination of the change in biomass. This was deduced from the initial (wet 
weight) at harvest and final weight (dry weight) after the entire plant was oven-dried until constant weight was attained. However any plant matter that was not collected for analysis was left in the green house in airtight containers for later use and appropriate disposal. Following the sampling, the following were determined:

- Final PCB in soil and PCB recovery in plant tissues after six weeks of treatment with transformer oil co-contaminated with Aroclor 1260 using GC-MS.

- Analysis and quantification of total PCB recovery in extracts from soil and plant samples using the USEPA modified 8089/8081 method for the determination of total PCB (USEPA, 1997). The analysis was conducted using Agilient 7890 GC equipped with 5975 Mass Spectometry and auto injector, an SupelcoWAX SPB ${ }^{\mathrm{TM}}-1$ (30 m x $\left.0.25 \mathrm{~mm} \times 0.25 \mu \mathrm{m}\right)$ column was used with $\mathrm{N}_{2}$ as the carrier gas. The initial content of PCB in transformer oil spiked was measured to be 6.8, 7.1, 6.1, 6.9, 6.3, and 6.7 in $\mathrm{T} / \mathrm{O}_{\mathrm{D}}$ and also 8.9, 7.4, 6.5, 7.3, 7.8, and $6.4 \mathrm{ppm}$ in $\mathrm{T} / \mathrm{O}_{\mathrm{s}}$.

\subsection{Statistical analysis of values}

Results were analyzed by analysis of variance using three replicates at $95 \%$ level of significant difference to determine the mean differences of treatments in the experiment.

\section{Results}

\subsection{Soil and plants growth parameters}

The condition of the soil was slightly acidic, while other parameters indicated that $C$. odorata roots including the soil organisms will not have any resistance to thrive. After six weeks of growth in soil treated with Transformer oil cocontaminated with Aroclor 1260, growth inhibition was observed in plants especially the direct treated samples; such inhibition was even harmful to plants in higher concentration of $500 \mathrm{ppm}$ of oil. There was improved growth of $C$. odorata in the soil cultured Suzuki method. Plant growth measured from the difference between the initial and final length of $C$. odorata is presented in Figure 1. Mean percentage growth rate was higher in $\mathrm{T} / \mathrm{O}_{\mathrm{S}}$ at $100 \mathrm{ppm}(17.01)$ than the $\mathrm{T} / \mathrm{O}_{\mathrm{D}}(1.40)$. Untreated control $\mathrm{C} 1$ have percentage growth rate of 43.3 which is significantly different from that of the treated samples $(\mathrm{p}=0.07)$. Relative mean Percentage growth rate at $200 \mathrm{ppm}$ were lower than in $100 \mathrm{ppm}$ treatment but were higher than the $500 \mathrm{ppm}$ respectively. Mean percentage growth rate of value less than zero (-1.03), was obtained in $\mathrm{T} / \mathrm{O}_{\mathrm{D}}$ at $500 \mathrm{ppm}$ treatment. Meanwhile, the growth of $C$. odorata was found to be negatively correlated with increase in concentration of soil transformer oil. In all treatments, percentage growth rate between treated and untreated control was significantly different at $\mathrm{p}=0.005$.

The number of mature leaf per plant (MLPP) of $C$. odorata at any interval of time was observed to be influenced by the presence of oil in its surrounding. In $\mathrm{T} / \mathrm{O}_{\mathrm{S}}$, MLPP values were higher; hence at $100 \mathrm{ppm}$ it was 50.0 but dropped to zero at $200 \mathrm{ppm}$ and remained in zero at $500 \mathrm{ppm}$ (Table 2). Relative mean Percentage change in MLPP at untreated control (C1) was higher than the treated samples; and such values were significantly different $(\mathrm{p}=0.013)$ from that of the treated experiments. Root lengths of $C$. odorata at different concentrations of transformer oil co-contaminated with $10 \%$ Aroclor 1260, maintained the same trend as observed in growth rate and MLPP. Percentage change in root length was high in T/O at $100 \mathrm{ppm}$ (50.60), which is not significant with that of untreated control (68.98). Root length at this treatment was however reduced considerably at 200 and $500 \mathrm{ppm}(20.34$ and -0.24$)$ respectively. In T/OD treatment, percentage change in root length was lower at $100 \mathrm{ppm}$ than in $\mathrm{T} / \mathrm{O}_{\mathrm{S}}$ and such effect was increased at higher concentrations. Results of root length of $C$. odorata after six weeks of growth in an Aroclor treated soil is presented in Figure 3 and Table 4. 

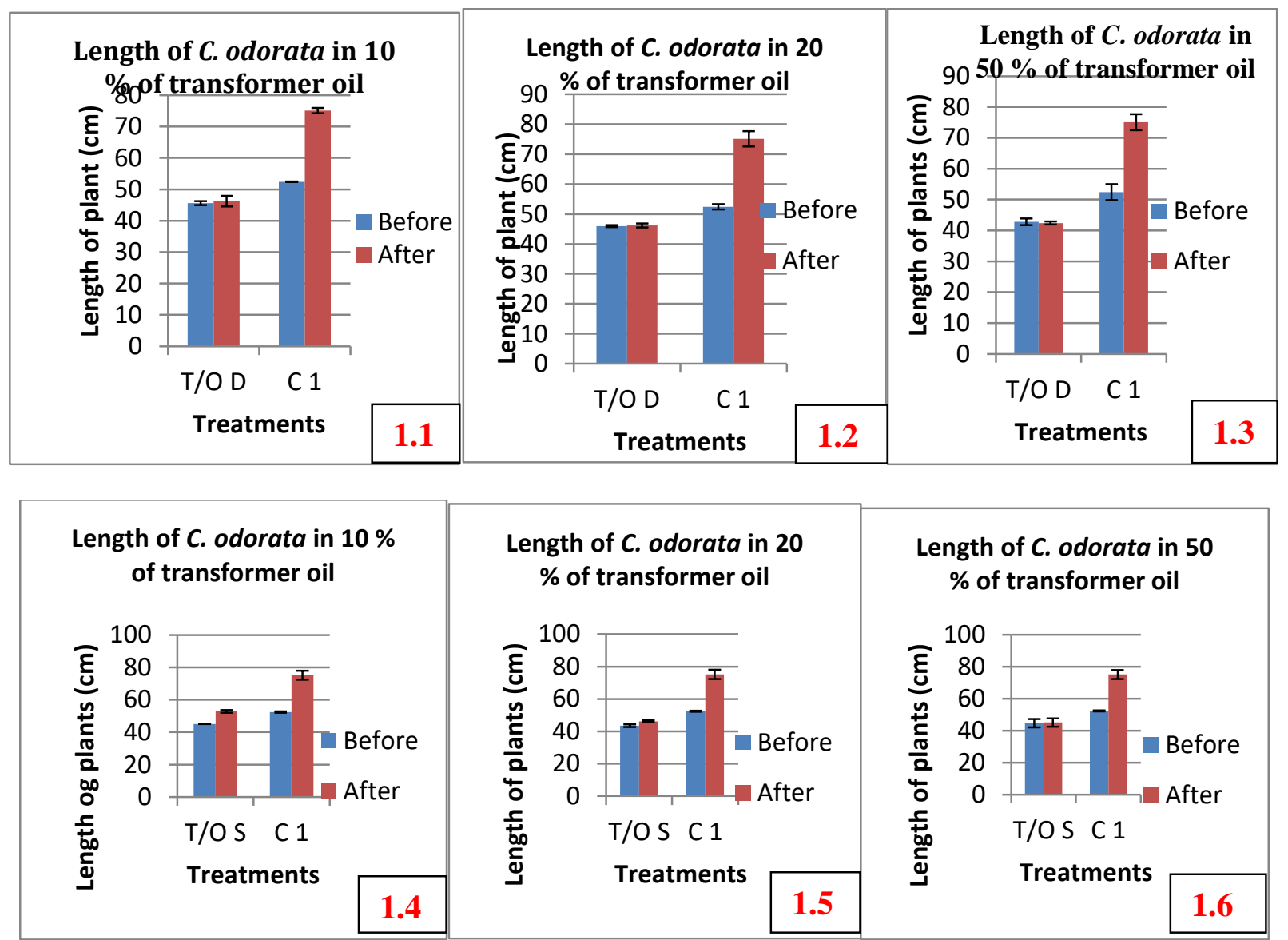

Figure 1: Length of plant at different concentrations of T/O co-contaminated with Aroclor 1260 in soil (Error bars indicate standard error of the mean), before=initial length, after=final length 


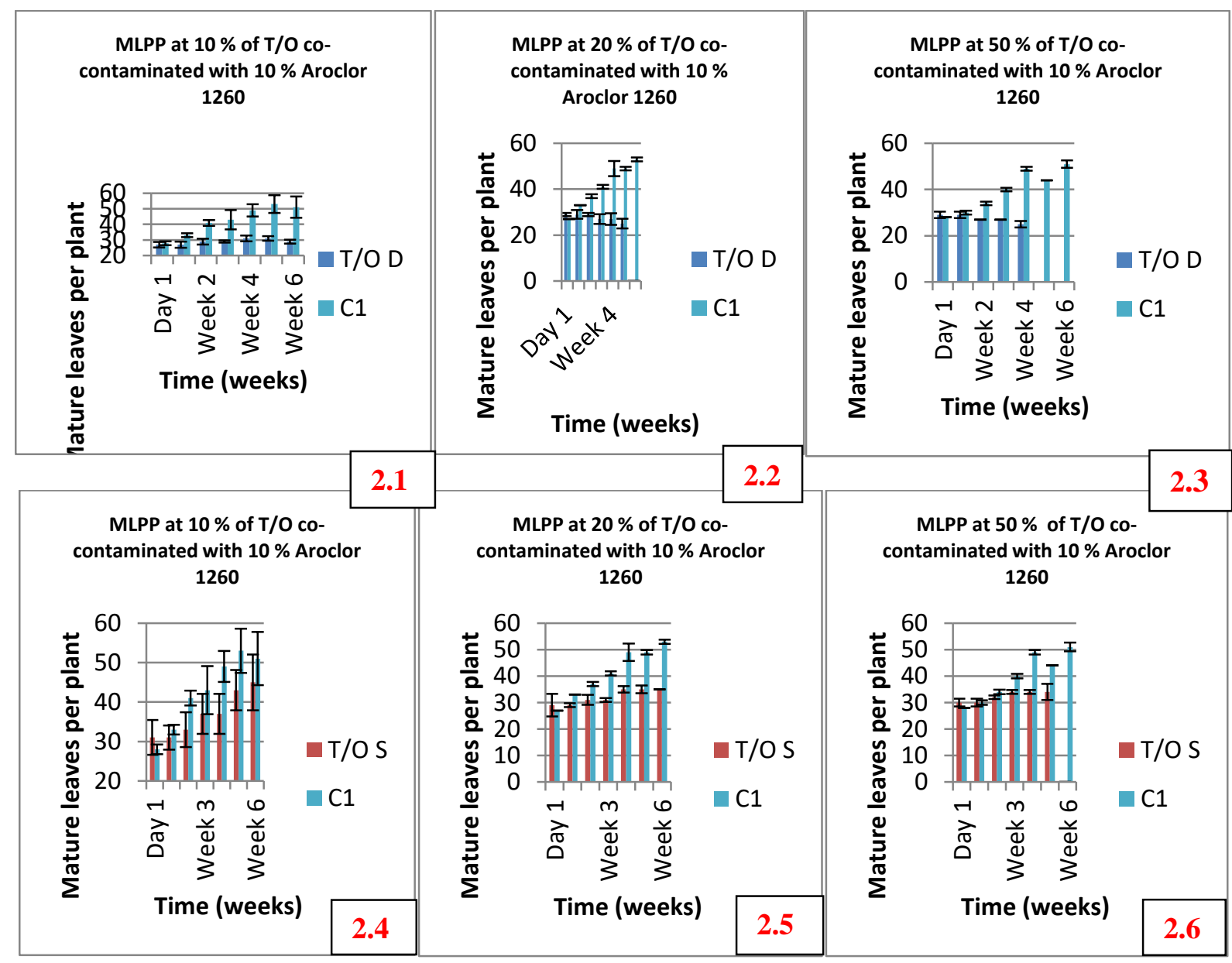

Figure 2: MLPP at different concentrations of T/O co-contaminated with Aroclor 1260 (Error bars indicate standard error of the mean), $\mathrm{T} / \mathrm{O}_{\mathrm{D}}=$ direct transformer oil, $\mathrm{T} / \mathrm{O}_{\mathrm{s}}=$ Suzuki transformer oil, $\mathrm{C} 1=$ control 1 , 

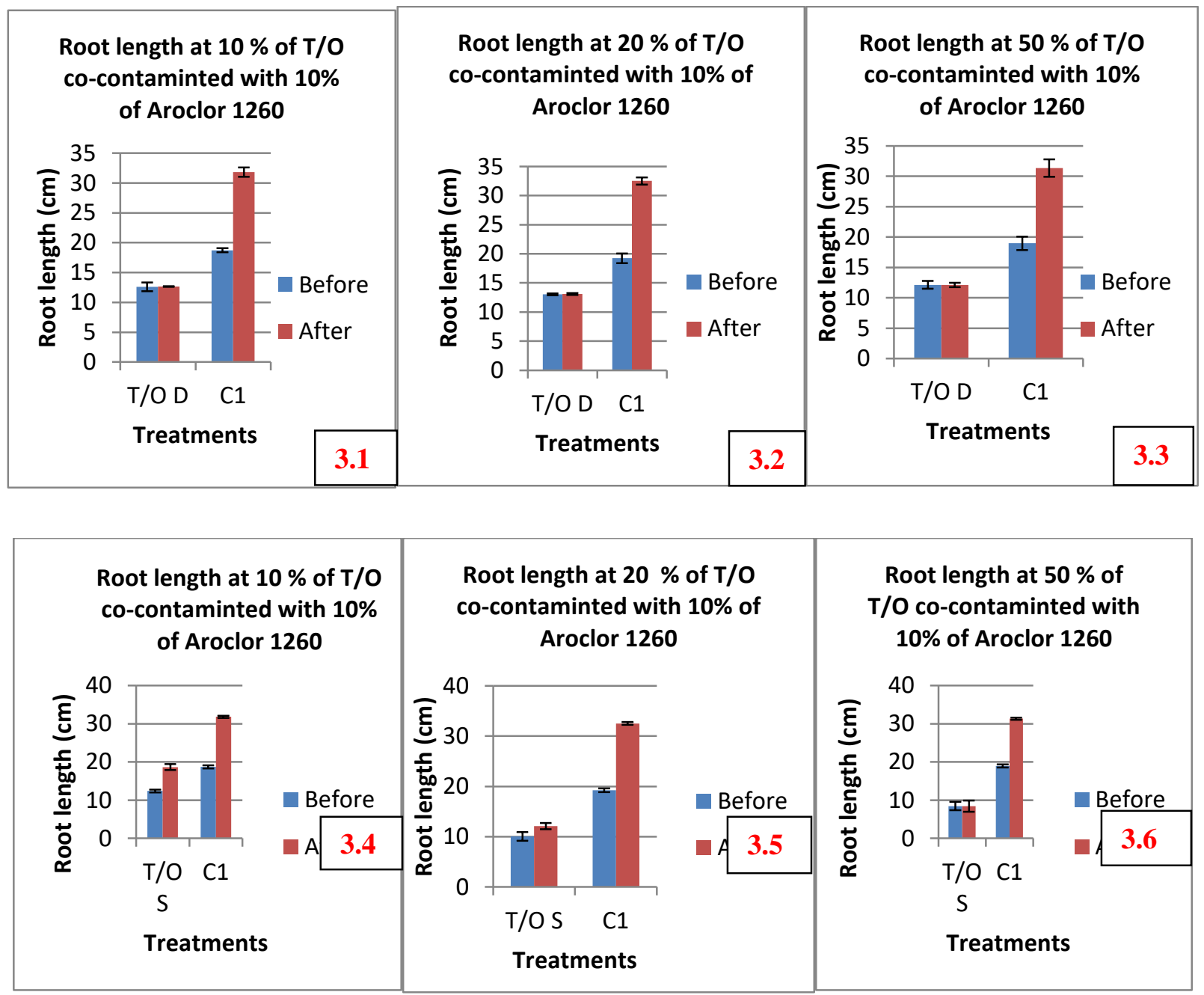

Figure 3: Root length at different concentration of Transformer oil co-contaminated with of Aroclor 1260 (Error bars indicate standard error of the mean), before=initial length, after=final length

Table 1: Percentage change in biomass of $C$. odorata at $100 \mathrm{ppm}$ of transformer oil co-contaminated with Aroclor 1260 treatments.

\begin{tabular}{|c|c|c|c|c|}
\hline $\begin{array}{l}\text { Treatments/Set- } \\
\text { up }(\mathrm{ppm})\end{array}$ & Wet weight (g) & Dry weight (g) & Difference (g) & $\%$ change \\
\hline$T / O_{D}$ & $5.69^{a}$ & $4.15^{a}$ & $1.54^{\mathrm{a}}$ & $27.07^{a}$ \\
\hline C1 & $\mathbf{1 3 . 0 6}^{\mathrm{b}}$ & $1.76^{a}$ & $11.30^{b}$ & $86.52^{b}$ \\
\hline $\mathrm{C2}$ & NP & NP & NP & NP \\
\hline $\begin{array}{l}\text { Treatments/Set- } \\
\text { up (ppm) }\end{array}$ & Wet weight (g) & Dry weight (g) & Difference (g) & $\%$ change \\
\hline $\mathrm{T} / \mathrm{O}_{\mathrm{S}}$ & $6.64^{\mathrm{a}}$ & $3.37^{a}$ & $3.27^{\mathrm{a}}$ & $49.25^{a}$ \\
\hline C1 & 13.06 $^{b}$ & $1.76^{\mathrm{a}}$ & $\mathbf{1 1 . 3 0}^{\mathrm{b}}$ & $86.52^{b}$ \\
\hline $\mathrm{C2}$ & NP & $\mathbf{N P}$ & NP & NP \\
\hline
\end{tabular}

Values with the same alphabets in superscript in the same column were not significant at 5\% level according to Bonferoni test. $\mathrm{T} / \mathrm{O}_{\mathrm{D}}=$ direct transformer oil, $\mathrm{T} / \mathrm{O}_{\mathrm{S}}=$ Suzuki transformer oil, $\mathrm{C} 1=$ control 1, $\mathrm{C} 2=$ control 2, NP=not palnted 
Table 2: PCB recovery results: final soil PCB concentration, total PCB concentration, percentage PCB absorbed, percentage change in PCB, and PCB concentration factor

\begin{tabular}{|c|c|c|c|c|c|}
\hline Treatments & $\begin{array}{l}\text { Initial soil } \\
\text { PCB } \\
\text { conc. } \\
\text { (ppm) }\end{array}$ & $\begin{array}{l}\text { Final soil PCB } \\
\text { conc. }(\mathbf{p p m})\end{array}$ & $\begin{array}{l}\text { Total PCB } \\
\text { in plants } \\
\text { tissue } \\
(\mathrm{ppm})\end{array}$ & $\begin{array}{ll}\% & \text { PCB } \\
\text { absorbed }\end{array}$ & $\begin{array}{l}\text { \% change in } \\
\text { PCB }\end{array}$ \\
\hline$T / O_{D} 100$ & 6.8 & 2.61 & -- & -- & 61.6 \\
\hline C1 & BD & BD & BD & BD & 0 \\
\hline $\mathrm{C2}$ & 6.9 & 5.42 & NP & NP & 21.4 \\
\hline $\mathrm{T} / \mathrm{O}_{\mathrm{D}} 200$ & 7.1 & 3.32 & -- & -- & 53.2 \\
\hline C1 & BD & BD & BD & BD & 0 \\
\hline $\mathrm{C2}$ & 6.3 & 5.27 & NP & $\mathbf{N P}$ & 16.3 \\
\hline $\mathrm{T} / \mathrm{O}_{\mathrm{D}} \mathbf{5 0 0}$ & 6.1 & 3.57 & -- & -- & 41.5 \\
\hline C1 & BD & BD & BD & BD & $\mathbf{0}$ \\
\hline $\mathrm{C2}$ & 6.7 & 5.44 & NP & $\mathbf{N P}$ & 18.8 \\
\hline $\mathrm{T} / \mathrm{O}_{\mathrm{s}} 100$ & 8.9 & 2.02 & -- & -- & 77.3 \\
\hline C1 & BD & BD & BD & BD & $\mathbf{0}$ \\
\hline $\mathrm{C2}$ & 7.3 & 6.08 & NP & $\mathbf{N P}$ & 16.7 \\
\hline$T / O_{s} 200$ & 7.4 & 1.87 & -- & -- & 74.7 \\
\hline C1 & BD & BD & BD & BD & $\mathbf{0}$ \\
\hline $\mathrm{C2}$ & 7.8 & 5.81 & NP & $\mathbf{N P}$ & 25.5 \\
\hline $\mathrm{T} / \mathrm{O}_{\mathrm{s}} \mathbf{5 0 0}$ & 6.5 & 2.68 & -- & -- & 58.8 \\
\hline C1 & BD & BD & BD & BD & $\mathbf{0}$ \\
\hline $\mathrm{C2}$ & 6.4 & 5.05 & NP & NP & 21.1 \\
\hline
\end{tabular}

Conc. $=$ concentration, $\mathrm{BD}=$ below detection, $\mathrm{NP}=$ not planted, $\mathrm{RF}=$ remediation factor, $\mathrm{T} / \mathrm{O}_{\mathrm{D}}=$ direct transformer oil, $\mathrm{T} / \mathrm{O}_{\mathrm{S}}=\mathrm{Suzuki}$ transformer oil, $\mathrm{C} 1=$ control $1, \mathrm{C} 2=$ control 2

\section{Discussion}

\subsection{Growth of $C$. odorata in transformer oil contaminated soil}

Phytoremediation of PCB co-contaminated in transformer oil in form of $100 \mathrm{ppm}$ of Aroclor by C. odorata in this study behaved differently at different concentrations of transformer oil in the soil. This could be attributed to the toxicity of transformer/hydrocarbon containing oil in plants. Increase in concentration of oil in soil has been reported to increase the phytoxicity in plants until such concentration that it became harmful to the plants [8-12]. In this study, the growth of $C$. odorata was tremendously affected by the presence of transformer oil in the soil especially when the oil is in direct contact with the plant $\left(\mathrm{T} / \mathrm{O}_{\mathrm{D}}\right) .500 \mathrm{ppm}$ of transformer oil per kilogram of soil was toxic to $C$. odorata at this treatment.

Mature leaves per plant were increased especially in the lower oil treatments an indication of growth among the plants growing in that contaminated soil. However, the higher oil concentration of 200 and $500 \mathrm{ppm}$ contributed in the reduction of plants growth rate to 1.08 and $6.09 \%$ respectively within the Suzuki ammended experiment with a faint increase in MLPP in $200 \mathrm{ppm}$ of oil, but withering of the plants was observed at the $500 \mathrm{ppm}$ of both Suzuki method as well as in direct treatment with transformer oil as a result it could not develop more leaves. Untreated control maintained a high growth percetage increase in MLPP with values significantly different from those of T/OD and T/OS treatments. This result therefore is in aggreement with the fact that exposure of plants to a concentration higher than what it can tolerate may cause chlorosis of the leaves, plants dehydration, stunted growth and also death $[2,5]$.

This study presented an average shoot to root ratio range of $4: 1$ to $13: 1$. This ratio is within the range observed by one of the first studies on phytoremediation using a field tobacco plant [11]. The study reported that plants with low 
concentration of organics could still extract a valuable quantity of PCBs with a large shoot biomass. Contrastingly this study could not obey the model reported by literature, but proffers a higher root biomass increase which explains the reason why PCB absorption by the plant was concentrated in the root tissue [10]. Percentage change in biomass at T/OD and T/OS was significantly different from each other and an increase in their value was observed as the concentration was increased from 100 to 200 to $500 \mathrm{ppm}$. This explains the fact that the presence of transformer oil in soil containing C. odorata affects transpiration ability of the plants thence affecting its physiological responses [10-11]. Such increased trend was also significantly different from that of untreated control which recorded all time high of above $89 \%$.

In transformer oil amended soil treatments, the concentrations of PCB in different oil treatments were not phytotoxic to C. odorata as the plant has been shown to survive $500 \mathrm{ppm}$ of PCB concentration in authors previous study hence was able to complete the growth duration of the experiment in those treatments. That is to say if the plant could manage the inhibition of the transformer oil then there is possibility of phytoremediation of the PCB content as observed in different concentration of transformer oil in the experiment. There was no measurement of concentration of the oil at the end of the experiment but the influence of the oil was observed on the percentage reduction of PCB in the experiment. Percentage reduction of $\mathrm{PCB}$ in the experiment was high at the lower transformer oil treatment but continued to decrease as the content of oil was increased [12-13,21]. The severity of transformer oil on growth of C. odorata throughout the duration of this experiment at higher concentration of the oil may not have been caused by co-treatment with Aroclor as the plant was found to survive at much higher PCB-concentrated soil (Authors unpublished work). This implies that it could have been caused by oil inhibition and perhaps other factors not measured. However, total PCB concentrations found in the root tissues of C. odorata, ranges from 0.10 to $0.11 \mathrm{ppm}$, the values could not give any remediation factor for the plants as a result of the fact that such presence of PCB was not found in the above ground tissues of the plant. Therefore C. odorata only absorbed PCB at 100 and 200 ppm transformer oil per kilogram of soil in the Suzuki experiment. Such effect was not possible at $500 \mathrm{ppm}$ concentrations as well as in the direct treatment of the soil with T/O. This is in agreement with the study of Pinsker [14-16], which reported that initial soil PCB has a great effect on the amount of PCB absorbed by plants, its translocation as well as the concentrations of the residual PCB in the soil at the end of a phytoremediation study. There was higher mean percentage reduction of $\mathrm{PCB}$ concentration in the entire experiment compared to the mean percentage PCB reductions of other plants species in phytoremediation studies reported in literature per unit time [15-22]. However PCB reduction was also observed at the unplanted control, the reason behind such observation could be attributed to natural attenuation and perhaps other parameters not measured.

However, future studies should involve the analysis of the resultant compound from the degradation of Aroclor 1260 in the presence of transformer oil by the root of $\mathrm{C}$. odorata to enable a conclusive result to be drawn.

\section{Conclusions}

The results of this study showed that the presence of transformer oil in soil at both low and high concentration inhibits C. odorata growth parameters, hence reduces the ability of the plant to phytoremediate soil PCB. The presence of C. odorata in this experiment contributed in the remediation of the soil at low co-contamination of the oil, but the effects of the plants were negatively impacted at high co-contamination of the oil at direct contact with the plant.

\section{Acknowledgement}

Authors wish to acknowledge the financial support given by the South African National Research Foundation (NRF) and University of South Africa (UNISA) on this project.

\section{References}

[1] S. Susarla, V. F. Medina S. C. McCutcheon, "Phytoremediation: An organic solution to chemical contamination," Ecol Eng, vol. 18, no. 5, pp. 647-658, 2002.

[2] R. O, Anyasi, H. I. Atagana Biological remediation of polychlorinated biphenyl (PCB) in the environment by microorganisms and plants. Afr J Biotechnol, vol. 10, no. 82, pp. 18916-18938, 2011.

[3] Y. Chang, G. Achari, C. Langford, "Effect of Cocontaminants on the Remediation of PCB-Impacted Soils by Hydrogen Peroxide”. Pract Period Haz Toxic Rad Waste Manage, vol.14, no. 4, pp. 266-268, 2010. 
[4] S. A. Ficko, A. Rutter, B. A. Zeeb, "Phytoextraction and uptake patterns of weathered polychlorinated biphenylscontaminated soils using three perennial weeds species,"J Environ Qual, vol. 40, no. 6, pp. 1870-1877, 2011.

[5] I. A. R. Gray, A guide to transformer oil analysis. Gray transformer chemistry services, pp. 1-12, 2010.

[6] US EPA. Method 1613, Revision B, Tetra- through octachlorinated dioxins and furans by isotope dilution HRGC/ HRMS, September 15, 1997, 40 CFR 136 (FR 48405), Washington, DC., pp. 79,1997

[7] 7, H. I. Atagana, "Bioremediation of co-contamination of crude oil and heavy metals soil by phytoremediation using Chromolaena odorata (L) King \& H.E. Robinson," Water Air Soil Poll, vol.215, no. 1-4, pp. 261-271, 2011 a.

[8] H. I. Atagana, 2011a. "The potential of Chromolaena odorata (L) to decontaminate used engine oil impacted soil under greenhouse conditions," Int J Phytorem, vol. 13, no. 7, pp. 627-641.

[9] S. Singh, V. Thorat, C. P. Kaushik, K. Raj, , S. F. D’Souza, "Potential for Chromolaena odorata for phytoremediation of ${ }^{137}$ Cs from solution and low level nuclear waste," J Haz Mat, vol. 162, no. 2-3, pp. 743-745, 2009.

[10] S. A. Ficko, A. Rutter, B. A. Zeeb, "Potential for phytoextraction of PCBs from contaminated soils using weeds," Sci Total Environ, vol. 408, no. pp. 3469-3476, 2010.

[11] E. Sobiecka, K. Cedzynska, C. Bielski, B. Antizar-Ladislao, "Biological treatment of transformer oil using commercial mixtures of microorganisms," Intern Biodeter Biodegrad, vol. 63, no. 3, pp. 328-333, 2009.

[12] M. Suzuki, N. Aizawa, G. Okano, T. Takahashi, "Translocation of Polychlorobiphenyls in soil into plants: A study by a method of culture of soybean sprouts," Arch Environ Contam Tox," vol. 5, no. 1, pp. 343-352, 1977.

[13] I. J. Gler, Root systems of bright belt tobacco. Amer J Bot, vol. 27, no. (a): 780-787, 1940.

[14] N I. Pinsker, "Phytoremediation of PCB-contaminated soil: Effectiveness and regulatory policy," MSc. Thesis, Virginia Commonwealth Universisty, pp. 56-73, 2011.

[15] M. Mackova, P. Petra, S. Petr, R. Edita, U. Ondrej, B. Katarina, R. Jan, K. Veroniva, D. Katerina, M. Tomas, "Phytoremediation studies using long term PCB contaminated soil," Environ Sci Poll Res, vol. 16, no. 7 pp. 817-829, 2009.

[16] P, Tanhan, P. Pokethitiyook, M. Kruatrachue, R. Chaiyarat, S. Upatham, "Effects of soil amendments and EDTA on lead uptake by Chromolaena odorata: Greenhouse and Field Trial Experiments," Inter J Phytorem, vol. 13, no. 9, pp. 897-911, 2011.

[17] R. O. Anyasi, H. I. Atagana, "Profiling of plants at petroleum contaminated site for phytoremediation," Int J Phytorem, vol. 20, no. 4, pp. 352-364. 2018.

[18] R. O. Anyasi, 'Bioremediation of polychlorinated biphenyls (PCB)-contaminated soil by phytoremediation with Chromolaena odorata (L) King and Robinson,” MSc thesis, University of South Africa, pp. 50-169, 2012.

[19] Eskandary S, Tahmourespour A, Hoodaji M, Abdollahi, A. "The synergistic use of plant and isolated bacteria to clean up polycyclic aromatic hydrocarbons from contaminated soil," J Environ Health Sci Eng, vol, 15, no. 12, pp. 1-8, 2017.

[20] E. K. Mitter, R. Kataoka, J. R. de Freitas, J. J. Germida, "Potential use of endophytic root bacteria and host plants to degrade hydrocarbons," Int J Phytorem, vol. 21, no. 9, pp. 928-938. 2019.

[21] K. J. Umar, M. J. Muhammad, N. A. Sani, S. Muhammad, M.T. Umar, "Comparative Study of Antioxidant Activities of the Leaves and Stem of Ipomoea aquatica Forsk (Water Spinach)," Niger J Basic Appl Sci, vol. 23, no. pp. 81-84, 2015.

[22] H. Sarma, "Metal hyper accumulation in plants: A review focussing on phytoremediation technology," J Environ Sci Technol, vol. 4 no. 2, pp. 118-138, 2011. 